\title{
Scoring Systems and Risk Stratification in Cirrhotic Patients with Acute Variceal Bleeding "Scoring in Variceal Bleeding"
}

\section{Asmaa Naser Mohammad ${ }^{\star}$ and Khairy Hammam Morsy}

Department of Tropical Medicine and Gastroenterology, Sohag University Faculty of Medicine, Sohag, Egypt

*Corresponding author: Asmaa Naser Mohammad, Department of Tropical Medicine and Gastroenterology, Sohag University, Egypt, Tel: +201003396041; E-mail: asmaanaser25@yahoo.co.uk

Rec date: April 20, 2016; Acc date: May 06, 2016; Pub date: May 20, 2016

Copyright: (c) 2016 Mohammad AN, et al. This is an open-access article distributed under the terms of the Creative Commons Attribution License, which permits unrestricted use, distribution, and reproduction in any medium, provided the original author and source are credited.

\begin{abstract}
Objectives: To find the most accurate, suitable and applicable scoring system used for prediction of outcome in cirrhotic patients with bleeding varices.

Methods: This prospective study included 120 cirrhotic patients with acute variceal bleeding, admitted at Department of Tropical Medicine and Gastroenterology in Sohag University Hospital over a one-year period (1/2015 to 1/2016). Clinical, laboratory and endoscopic parameters were studied, Child-Pugh (CTP) classification score, Model for end-stage liver disease (MELD) score, Acute physiology and chronic health evaluation II (APACHE II) score, sequential organ failure assessment (SOFA) score and AIMS65 score were calculated for all patients, univariate, multivariate analysis and performance was performed for all taken parameters and the scores.
\end{abstract}

Results: The 120 patients (92 male, 28 female) admitted during the study period, eight patients $(6.67 \%)$ died in hospital. Higher age, presence of encephalopathy, rebleeding, and higher serum bilirubin were independent factors associated with higher hospital mortality. The largest area under the receiver operator curve (AUROC) was for AIMS65 score and SOFA score followed by MELD score and APACHEII score then Child score all of which achieved very good performance (AUROC > 0.8). AIMS 65 score has the best sensitivity, specificity negative and positive predictive values. Although AIMS65 score was not significantly different from MELD, SOFA, and APACHEII scores, it was the best among them in prediction of mortality.

Conclusions: AIMS65 score is best simple and applicable scoring system to independently predict mortality in those patients.

Keywords: AIMS65; Liver cirrosis; Variceal bleeding

\section{Introduction}

Acute upper gastrointestinal (GI) bleeding is a frequent cause of hospital emergency admissions worldwide [1]. Acute variceal hemorrhage $(\mathrm{AVH})$ is the most dangerous complication of portal hypertension as it is associated with significantly higher morbidity and mortality [2]. The prognosis for cirrhotic patients associated with liver disease severity [3]. Child- pugh classification used to assess the severity of liver disease, higher scores significantly affects survival time. The mortality rate after the first episode of bleeding ranges from $15 \%$ to $80 \%$ and is higher with child's class B and C (60\% to 80\%) than with class A (15\%) [4]. Many factors have been studied and found to be associated with increased risk of mortality in patients with bleeding varices [5]. When cirrhotic patients admitted to intensive care unit, the use of liver prognostic models as child-pugh and MELD scores were found to be poor predictors of outcome [6]. But in patients with acute variceal hemorrhage it still remains unclear if these models could do well for risk stratification among this group of patients.

Our aim is to evaluate the outcome of patients presented to our tertiary referral center with acute variceal bleeding and to study the best of the prognostic models for prediction of this outcome.

\section{Patients and Methods}

This prospective study included all adult cirrhotic patients admitted to Sohag University Hospital, Tropical Medicine Department with acute variceal bleeding (in the form of haematemesis, melena, and or bloody fluids either as vomitus or drained by nasogastric tube) from $1 / 2015$ to $1 / 2016$.

The study was approved by the local ethics committee in Sohag faculty of medicine.

\section{Inclusion criteria}

Cirrhotic patients presented by bleeding varices (esophageal, fundal or both).

\section{Exclusion criteria}

Patients diagnosed to have other causes of upper GIT bleeding (such as: peptic ulcer disease, reflux esophagitis, erosions, antral vascular ectasia) previously or at endoscopy after admission.

A complete history, thorough physical examination, monitoring of vital signs, to all patients were done.

Liver function and serum creatinine were assessed on admission and serially during hospitalization. Complete blood count, serum 
Page 2 of 5

electrolytes, arterial blood gases, and number of units of blood received were recorded.

All patients underwent upper endoscopy and therapy was initiated according to the endoscopic findings, all the endoscopic finding were described according to the Japanese research society for portal hypertension [7].

Urine analysis, chest $\mathrm{X}$-ray, and ascitic fluid analysis, were performed to detect sources of infection.

All patients underwent abdominal ultra-sonography and testing for the surface antigen of the hepatitis $\mathrm{B}$ virus (HBsAg) and hepatitis $\mathrm{C}$ virus antibodies (HCV Abs).

Prognostic scores were calculated from data collected on the 1st day of admission. Child-Turcotte-Pugh (CTP) score, model for end-stage liver disease (MELD), acute physiology and chronic health evaluation II (APACHE II) score and sepsis-associated organ failure assessment (SOFA) score were calculated according to the Pugh modification [8], United Network of Organ Sharing adjustments [9], Knaus et al. [10] Vincent et al. [11].

AIMS65 score was calculated according to Saltzman et al. [12], it was recently developed, this risk score could predicts in-hospital mortality, length of stay, and cost in patients with acute UGIB. The new score compromised from the following parameters: level of albumin less than $3.0 \mathrm{~g} / \mathrm{d} \mathrm{L}(\mathrm{A})$, international normalized ratio (INR) more than 1.5 (I), mental status alteration $(\mathrm{M})$, systolic blood pressure $\leq 90$ $\mathrm{mmHg}(\mathrm{S})$, and age more than sixty five years. When more than two components of AIMS65 are present, the mortality risk is considered to be high.

\section{Hypovolaemic shock}

It was defined as the presence of decrease in systolic blood pressure into $<90 \mathrm{mmHg}$; tachycardia $>100$ beats/minute; and a decreased central venous pressure or jugular venous pressure [13].

Rebleeding is recurrent vomiting of blood, and/or melena with shock and/or decrease of at least $2 \mathrm{~g} / \mathrm{d} \mathrm{L}$ in hemoglobin concentration after initial treatment, resuscitation and/or indicated endoscopic therapy [14].

\section{Transfusion requirements}

The whole blood units and/or blood products needed to the admitted patient on the day of admission or five days afterword [15].
Blood transfusions initiated when the hemoglobin is less than 7 $\mathrm{g} / \mathrm{dL}$ when there is no associated illness, our aim is to reach a level $\geq 7$ $\mathrm{g} / \mathrm{dL}$. However, in patients presenting with UGIB and suffering from coronary artery disease, we need to reach hemoglobin level $\geq 9 \mathrm{~g} / \mathrm{dL}$ to avoid adverse events of significant anemia. Fresh frozen plasma (FFP) or platelets transfused to patients with coagulopathy or uncontrolled bleeding and/or a severe thrombocytopenia $(<50,000 / \mu \mathrm{L})[16]$.

\section{Esophageal balloon temponade}

It was used when bleeding is rapid with haemodynamic instability before endoscopy.

\section{Statistical analysis}

Chi squared test or Fisher's exact test were used to analyze the data as appropriate. Univariate and multivariate analysis will be performed using logistic regression models.

\section{Results}

A total of 120 patients (92 male, 28 female) were admitted to our department over a period of one year due to acute upper GIT bleeding with bleeding attributed to gastroesophageal varices (GEV).

Demographic, clinical, laboratory, and endoscopic data are shown in Table 1.

The etiology of liver cirrhosis was HCV in 95 patients $(79.17 \%)$ $\mathrm{HBV}$ in 5 patients $(4.17 \%)$, infection with $\mathrm{HBV}$ and $\mathrm{HCV}$ in 2 patients $(1.67 \%)$ and unknown in 18 patients (15\%).

Infections were present in 16 patients including chest infection, spontaneous bacterial peritonitis (SBP), and bed sores. Hepatic encephalopathy was found in 28 patients, rebleeding occurred in 8 patients and, portal vein thrombosis (PVT) in 7 patients from 23 patients diagnosed hepatocellular carcinoma (HCC).

As regard the endoscopic findings: Esophageal varices were found in 105 patients, gastric varices were found in 6 patients, while 9 patients were found to have both gastric and esophageal varices.

Endoscopic interventions the patients, 107 patients had band ligation, 9 had histoacryle injection and 4 patients had both band ligation and histoacryle injection.

In our study 8 patients (6.67\%) died, clinical characteristic of studied population in survivors and non survivors is shown in Table 1.

\begin{tabular}{|l|l|l|}
\hline Parameter & Survivors 112 (93.33\%) & Non- survivors 8 (6.67\%) \\
\hline Age Mean (SD) & $56.94(9.20)$ & $64.75(16.69)$ \\
\hline Male Sex & $85(75.89 \%)$ & $7(87.50 \%)$ \\
\hline Female sex & $27(24.11 \%)$ & $1(12.5 \%)$ \\
\hline Hypovolemic shock at admission & $16(14.29 \%)$ & $3(37.50 \%)$ \\
\hline Melena & $95(84.82 \%)$ & $8(100 \%)$ \\
\hline Presence of encephalopathy & $20(17.86 \%)$ & $8(100 \%)$ \\
\hline Need for balloon temponade & $57(50.89 \%)$ & $5(62.50 \%)$ \\
\hline Presence of infection & $11(9.82 \%)$ & 0.11 \\
\hline
\end{tabular}


Citation: Mohammad AN, Morsy KH (2016) Scoring Systems and Risk Stratification in Cirrhotic Patients with Acute Variceal Bleeding "Scoring in Variceal Bleeding". J Liver 5: 195. doi:10.4172/2167-0889.1000195

Page 3 of 5

\begin{tabular}{|c|c|c|c|}
\hline Re-bleeding & $4(3.57 \%)$ & $4(50.00 \%)$ & $0.001^{*}$ \\
\hline No. of transfused blood units Mean (SD) & $1.18(1.57)$ & $0.88(0.83)$ & 0.99 \\
\hline $\mathrm{HCC}$ & $22(19.64 \%)$ & $1(12.50 \%)$ & 1 \\
\hline \multicolumn{4}{|l|}{ Etiology of cirrhosis } \\
\hline $\mathrm{HCV}$ & $89(79.46 \%)$ & $6(75.00 \%)$ & \multirow[t]{4}{*}{0.77} \\
\hline HBV & $5(4.46 \%)$ & 0 & \\
\hline HBV \&HCV & $2(1.79 \%)$ & 0 & \\
\hline Unknown & $16(14.29 \%)$ & $2(25.00 \%)$ & \\
\hline \multicolumn{4}{|l|}{ Co-morbidity } \\
\hline No & $73(65.18 \%)$ & $5(62.50 \%)$ & \multirow[t]{5}{*}{0.43} \\
\hline DM & $32(28.57 \%)$ & $2(25.00 \%)$ & \\
\hline DM, HTN & $2(1.79 \%)$ & $1(12.50 \%)$ & \\
\hline DM, HTN, COPD & $1(0.89 \%)$ & 0 & \\
\hline HTN & $4(3.57 \%)$ & 0 & \\
\hline Albumin Mean (SD) & $2.72(0.55)$ & $2.23(0.25)$ & $0.01^{*}$ \\
\hline Bilirubin Mean(SD) & $1.85(1.48)$ & $4.94(2.87)$ & $0.001^{*}$ \\
\hline INR Mean (SD) & $1.38(0.21)$ & $1.56(0.14)$ & $0.02^{*}$ \\
\hline Prothrombin time Mean (SD) & $15.71(2.39)$ & $17.58(1.24)$ & $0.03^{*}$ \\
\hline Prothrombin concentration Mean (SD) & $64.39(12.81)$ & $52.56(5.52)$ & $0.01^{*}$ \\
\hline S. creatinine Mean (SD) & $1.25(0.53)$ & $1.79(0.66)$ & $0.02^{*}$ \\
\hline \multicolumn{4}{|l|}{ Size of varices } \\
\hline F1 & $9(8.04 \%)$ & $1(12.50 \%)$ & \multirow[t]{8}{*}{0.98} \\
\hline F2 & $68(60.71 \%)$ & $4(50.00 \%)$ & \\
\hline F3 & $26(23.21 \%)$ & $3(37.50 \%)$ & \\
\hline Esophagus F1- Gastric F1 & $2(1.79 \%)$ & 0 & \\
\hline Esophagus F1- Gastric F2 & $2(1.79 \%)$ & 0 & \\
\hline Esophagus F2- Gastric F2 & $2(1.79 \%)$ & 0 & \\
\hline Esophagus F3- Gastric F1 & $2(1.79 \%)$ & 0 & \\
\hline Esophagus F3- Gastric F2 & $1(0.89 \%)$ & 0 & \\
\hline \multicolumn{4}{|l|}{ Endoscopic intervention } \\
\hline Band ligation & $99(88.39 \%)$ & $8(100 \%)$ & \multirow[t]{3}{*}{0.59} \\
\hline Histoacyl injection & $9(8.04 \%)$ & 0 & \\
\hline Both & $4(3.57 \%)$ & 0 & \\
\hline
\end{tabular}

Table 1: Comparing demographic, clinical, laboratory and endoscopic findings in survivors and non-survivors. 
There was a significant difference between survivors and non survivors as regard the presence of encephalopathy $(\mathrm{p}<0.0001)$, infection $(\mathrm{p}=0.001)$ and rebleeding $(\mathrm{p}=0.001)$ (Table 1$)$.

Upon studying the laboratory and endoscopic characteristics in survivors and non-survivors we found that:

The non survivors had significantly lower albumin level $(2.23( \pm$ $0.25)$ Vs.2.72 $( \pm 0.55), \mathrm{mg} / \mathrm{dl}, \mathrm{p}=0.01)$ and higher bilirubin $(4.94( \pm$ $2.87)$ vs. $1.85( \pm 1.48) \mathrm{mg} / \mathrm{dl}, \mathrm{p}=0.001)$, with higher INR $(1.56( \pm 0.14)$ vs. $1.38( \pm 0.21), \mathrm{p}=0.02)$ with more prolonged prothrombin time $(\mathrm{p}=0.03)$ and decreased prothrombin concentration $(\mathrm{p}=0.01)$.

Site, size of varices or type of endoscopic therapy didn't influence mortality (Table 1).

Hospital mortality was significantly high with Child C $(87.5 \%$ vs. $26.79 \%) \mathrm{p}=0.001$, MELD score $>18(\mathrm{p}=0.0003)$, APACHE II score $>14$ $(\mathrm{p}=0.0006)$, SOFA score $>7(\mathrm{p}=0.0001)$ and AIMS65 score $>2$ $(\mathrm{p}=0.0001)$.

By multivariate analysis we found that Higher age, presence of encephalopathy, rebleeding, and higher serum bilirubin were an independent factors for prediction of hospital mortality.

We analyze the prognostic risk stratification models in predicting hospital mortality; AIMS65 score and SOFA score found to have the largest area under the receiver operator curve (AUROC) was for followed by MELD score and APACHEII score then Child score, all of which achieved very good performance (AUROC $>0.8$ ).

Pairwise comparison of (AUROC) showed no significant difference between AIMS65, MELD, SOFA, and APACHEII scores $(p<0.05)$. However, AIMS56 score was superior to with the best (AUROC) ( $p>$ 0.05). After evaluation of the performance of each model, AIMS 65 score has the best performance in prediction of mortality in patients with variceal bleeding, it has the higher sensitivity (100\%), and negative predictive value (100\%), but APACH II score has the highest specificity (98.2\%), and positive predictive value (75.0\%).

\section{Discussion}

In this study, we studied the factors associated with mortality in patients admitted to our hospital with AVH and liver cirrhosis and reported the outcome of those patients. Our in-hospital mortality (HM) rate of $7.67 \%$ is consistent with the experience from other centers. Although, this may be attributed to the relatively small sample size and including only patients who had an endoscopic intervention in our study. In 1998, Pauwels et al. [17] showed that in-hospital mortality in cirrhotic patients presented with acute variceal bleeding has decreased by $50 \%$ over the preceding 15 years. Chalasani et al. [18] in a large study over three years long reported that in-hospital mortality was $14.2 \%$. In another large series of 403 cirrhotic patients and variceal bleeding, Del Olmo, et al. [19] reported a mortality rate of $7.4 \%$.

In our study, older age was independently associated with hospital deaths following AVH this also previously reported by Das et al. [6] Du Cheyron et al. [20].

Our results revealed that increased serum bilirubin, presence of hepatic encephalopathy, and re-bleeding after endoscopy were independent predictors of mortality. These results are in line with Chojkier et al. [21] Afessa, et al. [22].
Magliocchetti et al. [23] further showed that Child-Pugh score, albumin level, encephalopathy, and GEV hemorrhage correlated with survival.

In our study, the type of endoscopic therapy (either band ligation, histoacryle injection, or both) and etiology of liver cirrhosis did not influence mortality and this correlates with findings of Hassanien et al. [24] However, presence of HCC and PVT were found also not to influence mortality and this does not correlate with this study.

In a large retrospective study of 403 cirrhotics with variceal bleed, renal failure with raised serum creatinine, post-gastroscopy rebleeding, and presence of HCC and hepatic encephalopathy were found to be independent predictors of mortality [25]. The occurrence of rebleeding was significantly associated with mortality, a factor also reported in the series of Bamba et al. [5].

Portal vein thrombosis has no statistically significant difference between survivors and non -survivors in our study. These findings are in accordance with those of Moataz Hassanien et al. [24], although tumor infiltration to the portal vein seemed to increase the portal pressure and may increase the risk of uncontrolled bleeding.

Increased requirement of blood /blood product transfusion was significantly associated with mortality, this finding correlates with that of Al-Freah et al. [15]. Who reported that there was a 7\% rise in hospital mortality with every unit increase in Packed RBCs transfusion on the day of admission. Increased requirements of blood transfusion was reported as a poor prognostic indicator with other researchers consistent with our finding $[5,26]$.

We found that AIMS65 score is the best for predicting mortality among the mentioned 5 scores having the highest area under the curve. It was previously reported to be good predictor of outcome in patients with acute upper gastrointestinal hemorrhage by Nakamura et al. [27]. Moreover, Hyett et al. [28] found that AIMS65 score was better than Glasgow-Blatchford score for outcome prediction in those patients.

Also we found that SOFA score is superior to MELD score, APACHEII score, and Child's score in prediction of mortality with Child's (CP) score having the least area under the curve.

Cholongitas et al. [29] also reported that SOFA score had better predictive value compared to APACHE II and CP scores.

The chid-pugh score had the worst performance, may be this is due to it doesn't include the kidney functions in its parameters [29]. However, this does not correlate with Afessa and Kubilis [21], who compared the prognostic performances of APACHE II and Child-Pugh score in 111 cirrhotic patients hospitalized for upper GI bleeding and did not find significant differences between the two scoring systems. In a single centre cohort of ICU admitted patients presented with acute upper gastrointestinal bleeding from varices Al-Freah et al. [15] found that MELD has the best performance as it could be best liver prognostic models and not significantly different from other ICU scoring models as predictors of outcome.

There are some limitations for this study including: First, it was performed in a single institution. Second, the relatively small sample size. Third, calculation of mortality was only during hospital admission, further follow up of the patients for 30 and 60 days was required. Finally, we only included patients who had an endoscopic intervention in our study. 


\section{Conclusion}

Older age, presence of sepsis, serum bilirubin levels, presence of hepatic encephalopathy and re-bleeding after gastroscopy were independent predictors of mortality in our patients with liver cirrhosis and variceal bleeding. AIMS65 score was a simple and applicable scoring system to independently predict mortality in patients with variceal bleeding with high performance.

\section{References}

1. Kapsoritakis AN, Ntounas EA, Makrigiannis EA, Ntouna EA, Lotis VD, et al. (2009) Acute upper gastrointestinal bleeding in central Greece: the role of clinical and endoscopic variables in bleeding outcome. Dig Dis Sci 54: 333-341.

2. Barkun AN, Bardou M, Kuipers EJ, Sung J, Hunt RH, et al. (2010) International consensus recommendations on the management of patients with nonvariceal upper gastrointestinal bleeding. Ann Intern Med 152: 101-113.

3. Balanzo J, Such J, Sainz S, Gonzalez D, Guarner C, et al. (1990) Long term survival and severe rebleeding after variceal sclerotherapy. Surgery, Gynecology \& Obstetrics 171: 489-492.

4. Carey WD (1990) Predictors of variceal bleeding: solving the puzzle. Am J Gastroenterol 85: 1426-1427.

5. Bambha K, Kim WR, Pedersen R, Bida JP, Kremers WK, et al. (2008) Predictors of early re-bleeding and mortality after acute variceal haemorrhage in patients with cirrhosis. Gut 57: 814-820.

6. Das V, Boelle PY, Galbois A, Guidet B, Maury E, et al. (2010) Cirrhotic patients in the medical intensive care unit: early prognosis and long-term survival. Crit Care Med 38: 2108-2116.

7. Ogihara T, Kikuchi K, Matsuoka H, Fujita T, Higaki J, et al. (2009) The Japanese Society of Hypertension guidelines for the management of hypertension (JSH 2009). Hypertens Res 32: 3-107.

8. Pugh RN, Murray-Lyon IM, Dawson JL, Pietroni MC, Williams R (1973) Transection of the oesophagus for bleeding oesophageal varices. Br J Surg 60: 646-649.

9. Barber K, Madden S, Allen J, Collett D, Neuberger J, et al. (2011) Elective liver transplant list mortality: development of a United Kingdom endstage liver disease score. Transplantation 92: 469-476.

10. Knaus WA, Draper EA, Wagner DP, Zimmerman JE (1985) APACHE II: a severity of disease classification system. Crit Care Med 13: 818-829.

11. Vincent JL, Moreno R, Takala J, Willatts S, De Mendonca A, et al. (1996) The SOFA (Sepsis-related Organ Failure Assessment) score to describe organ dysfunction/failure. On behalf of the Working Group on SepsisRelated Problems of the European Society of Intensive Care Medicine. Intensive care medicine 22: 707-710.

12. Saltzman JR, Tabak YP, Hyett BH, Sun X, Travis AC, et al. (2011) A simple risk score accurately predicts in-hospital mortality, length of stay, and cost in acute upper GI bleeding. Gastrointestinal endoscopy 74: 1215-1224.

13. Lee H, Hawker FH, Selby W, McWilliam DB, Herkes RG (1992) Intensive care treatment of patients with bleeding esophageal varices: results, predictors of mortality, and predictors of the adult respiratory distress syndrome. Crit Care Med 20: 1555-1563.

14. Barkun A, Sabbah S, Enns R, Armstrong D, Gregor J, et al. (2004) The Canadian Registry on Nonvariceal Upper Gastrointestinal Bleeding and
Endoscopy (RUGBE): Endoscopic hemostasis and proton pump inhibition are associated with improved outcomes in a real-life setting. The American Journal of Gastroenterology 99: 1238-1246.

15. Al-Freah M, Gera A, Martini S, McPhail M, Devlin J, et al. (2014) Comparison of scoring systems and outcome of patients admitted to a liver intensive care unit of a tertiary referral centre with severe variceal bleeding. Alimentary Pharmacology \& Therapeutics 39: 1286-1300.

16. Hébert PC, Wells G, Blajchman MA, Marshall J, Martin C, et al. (1999) A multicenter, randomized, controlled clinical trial of transfusion requirements in critical care. Transfusion Requirements in Critical Care Investigators, Canadian Critical Care Trials Group. N Engl J Med 340: 409-417.

17. Pauwels A, Fourdan O, Carbonell N (1998) Mortality from digestive hemorrhage for the last fifteen years. Gastroenterol Clin Biol 22: A27.

18. Chalasani N, Kahi C, Francois F, Pinto A, Marathe A, et al. (2003) Improved patient survival after acute variceal bleeding: a multicenter, cohort study. The American Journal of Gastroenterology 98: 653-659.

19. del Olmo JA, Peria A, Serra MA, Wassel AH, Benages A, et al. (2000) Predictors of morbidity and mortality after the first episode of upper gastrointestinal bleeding in liver cirrhosis. Journal of Hepatology 32: 19-24.

20. du Cheyron D, Bouchet B, Parienti JJ, Ramakers M, Charbonneau P (2005) The attributable mortality of acute renal failure in critically ill patients with liver cirrhosis. Intensive Care Medicine 31: 1693-1699.

21. Afessa B, Kubilis PS (2000) Upper gastrointestinal bleeding in patients with hepatic cirrhosis: clinical course and mortality prediction. Am J Gastroenterol 95: 484-489.

22. Chojkier M, Laine L, Conn HO, Lerner E (1986) Predictors of outcome in massive upper gastrointestinal hemorrhage. J Clin Gastroenterol 8: 16-22.

23. Magliocchetti N, Torchio P, Corrao G, Arico S, Favilli S (1997) Prognostic factors for long-term survival in cirrhotic patients after the first episode of liver decompensation. Italian Journal of Gastroenterology and Hepatology 29: 38-46.

24. Hassanien M, EL-Talkawy MD, Maged EG, El Ray A, Ali AA, et al. (2015) Predictors of In-Hospital Mortality in patients with hepatocellular carcinoma and Acute Variceal bleeding. Electronic physician 7: 1336-1343.

25. Conn HO, Bircher J (1994) Hepatic encephalopathy: syndromes and therapies. Bloomington, Illinois, Medi-Ed Press.

26. Carbonell N, Pauwels A, Serfaty L, Fourdan O, Lévy VG, et al. (2004) Improved survival after variceal bleeding in patients with cirrhosis over the past two decades. Hepatology 40: 652-659.

27. Nakamura S, Matsumoto T, Sugimori H, Esaki M, Kitazono T, et al. (2014) Emergency endoscopy for acute gastrointestinal bleeding: prognostic value of endoscopic hemostasis and the AIMS65 score in Japanese patients. Digestive Endoscopy 26: 369-376.

28. Hyett BH, Abougergi MS, Charpentier JP, Kumar NL, Brozovic S, et al. (2013) The AIMS65 score compared with the Glasgow-Blatchford score in predicting outcomes in upper GI bleeding. Gastrointestinal Endoscopy 77: 551-557.

29. Cholongitas E, Senzolo M, Patch D, Kwong K, Nikolopoulou V, et al. (2006) Risk factors, Sequential Organ Failure Assessment and Model for Endâ€stage Liver Disease scores for predicting short term mortality in cirrhotic patients admitted to intensive care unit. Alimentary Pharmacology \& Therapeutics 23: 883-893. 